\title{
DOES KAOLIN CLAY REALLY CREATE A PERFECT HYDRAULIC INTERFACE CONTACT BETWEEN MATERIALS?
}

\author{
EVy VEREECKENA ${ }^{*}$, PetRa Schůtová ${ }^{B}$, AND STAF ROELS ${ }^{C}$
}

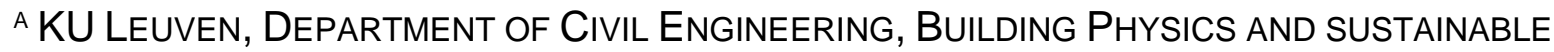
design, Kasteelpark Arenberg 40, B-3001 Leuven, Belgium, EVY.VEREECKEN@KULEUVEN.BE, TEL. +32 16321098

B UCEEB, CTU IN Prague, Třinecká 1024, 27343 Buštěhrad, Czech Republic

${ }^{c}$ KU Leuven, Department of Civil EngineeRing, Building Physics and sustainable Design, KasteelPaRk Arenberg 40, B-3001 Leuven, Belgium

"CORRESPONDING AUTHOR 


\section{Abstract}

In literature, kaolin clay is often put forward to create a perfect hydraulic contact across the interface of building materials. This paper studies, based on imbibition experiments, if kaolin clay truly nullifies a hydraulic interface resistance between materials. Thereto, a comparison is made between the water uptake by monolithic samples and by samples composed using kaolin clay. An interface resistance is observed and estimated to be in the order of $6000 \mathrm{~m} / \mathrm{s}$ to $12000 \mathrm{~m} / \mathrm{s}$ for a high absorptive brick and around $25000 \mathrm{~m} / \mathrm{s}$ for calcium silicate. For low absorptive materials or for an interface far from the water plain, a hydraulic interface resistance is probably also present. Though, in this case, the interface resistance is too low to have a noticeable impact on the cumulative inflow.

\section{Key words:}

hydraulic contact; kaolin clay; interface resistance; building composite; absorption coefficient; water uptake

\section{Introduction}

Moisture transfer in building components has an impact on durability, energy use and occupant's comfort. Typically, the analysis of moisture transport in building components focuses on the moisture transfer in single materials or in building components composed of just single building materials, neglecting interface phenomena occurring between the different materials (a.o. [1,2,3,4,5]). A perfect hydraulic contact is assumed. Yet, several studies showed that moisture transfer in 
multi-layered building elements can differ from the moisture transfer observed for the combination of the separate materials due to interface phenomena such as a mismatch of the pore structure of the materials in contact, compaction pores, mortar particles that penetrate into the material in contact with, micro-cracks as well as a change in (glue) mortar properties $[6,7,8,9,10,11,12,13]$. This deviation is projected in a deceleration of the moisture transport across the material interface [14,15,16], as if a hydraulic interface resistance is present, and can influence risk assessments. For instance, when dealing with rising damp in masonry, a decelerated moisture transfer can induce an elevated moisture level in the mortar and brick layers closer to the moisture source, which in its turn can result in enlarged risks on, for example, frost damage. Similarly, when neglecting the impact of an imperfect interface contact, the moisture level in repointed mortar joints could be underestimated, and again frost damage might be overlooked. A third representative example concerns the hygric performance of capillary active interior insulation systems. In the latter case, the inward moisture flow might be influenced and slowed down due to the interface phenomena between masonry and glue mortar and between glue mortar and capillary active insulation. Hence, a reliable risk assessment of masonry and multi-layered building elements in general demands a proper characterisation of the hydraulic interface phenomena. Four types of interface contact can be distinguished $[7,17,18]$, i.e (1) a perfect hydraulic contact with perfect continuity of the pore structure, which is as mentioned before unlikely, (2) a natural contact without continuity of the pore structure and no penetration of one of both materials in the other material, (3) an air layer and (4) a real (imperfect) hydraulic contact, with one of both materials penetrating into the pore structure of the 
other material. Several former studies on the moisture transfer across interfaces made use of kaolin clay, also indicated as China clay, to provide - as a reference - a perfect hydraulic contact between materials $[18,19,20]$. The capability of kaolin clay to offer such a perfect hydraulic contact has been put forward by Holm et al. [21], who achieved a perfect water uptake curve for a sample composed of two Rüthener sandstone specimen. The thin layer of kaolin clay in between the two samples was found to have no impact on the moisture transport during an imbibition experiment, as shown by the continuation of the initial slope. In absence of this kaolin clay, on the other hand, the curve showed a less steep slope once the moisture front had reached the interface. Driven by recent observation by the authors, however, the question arises if kaolin clay is truly effective in the creation of a perfect hydraulic interface contact. Therefore, this paper investigates, based on a series of imbibition experiments, to what extent the hydraulic interface resistance is nullified by use of kaolin clay at the interface between materials. This way, the outcome provides information on the possibility and reliability of using kaolin clay in further research on interface contact issues. Additionally, it can be of interest in the design of future test setups for material characterisation or, for instance, in studies on moisture and salt transport in building materials, as kaolin clay is also used in this context (a.o. [22,23]).

To analyse the effectiveness of kaolin clay, the water uptake curve measured for monolithic samples is compared to the water uptake curves achieved for samples with an equal total height but composed of two specimen of an identical material put together by use of kaolin clay. Both low and high absorptive materials are analysed. Additionally, the distance between the water plain and the contact interface resistance 
has been varied. Next, to assess the order of magnitude of a potential interface resistance, the experimental output is compared to numerical simulations. The paper is organised as follows. In Section 2, first the experimental test setup, the material properties and the numerical method applied to assess a potential interface resistance are described. Next, Section 3 presents the experimental results and compares those with numerical simulations. Ultimately, the results are discussed in Section 4 and the main conclusions are drawn in Section 5.

\section{Methodology}

\subsection{General principle}

To analyse the presence of a (perfect) hydraulic interface contact when applying kaolin clay, the water uptake curve of samples composed of two specimen of the same material put together by use of kaolin clay is compared to the water uptake curve achieved for monolithic samples. A difference between those curves denotes the presence of an imperfect hydraulic interface contact. To analyse the impact and order of magnitude of the interface resistance (if present), the experimental output is compared to numerical simulations.

\subsection{Test samples}

\subsubsection{Preparation and configurations}

Three series of test samples were prepared, i.e. two brick types (Brick 1, Brick 2) and a calcium silicate (CaSi), see Figure 1. This way, the impact of the moisture properties 
of the material specimen could be analysed (see Section 2.3 for the properties). The kaolin clay used to put the two specimen of the composite sample together was prepared by mixing kaolin powder with distilled water by a 1:1 mass ratio. By use of a putty knife, a thin coat of kaolin clay was applied with care to the contact surface of both specimen. To avoid that during the preparation of the composite samples the water of the kaolin clay would be absorbed by the test specimen, capillary moistened specimen were used. Next, both samples provided with kaolin clay were brought in contact with each other by gently sliding both kaolin clay surfaces. To keep a good contact between the specimen and the kaolin clay, the specimen were kept together by clamping screws. This way, the excess of kaolin clay was pushed from between both specimen and could be removed. Next, cable ties were put around the samples to keep a good contact between the specimen during the measurements (Figure 2). The composite samples had a total height of $16 \mathrm{~cm}$ and varied in distance between the contact interface and the water plain (see Table 1). As a reference, a monolithic sample of $16 \mathrm{~cm}$ high (Figure 1) was added to each of the test series. The exposure area of the test samples measured $4 \mathrm{~cm}$ by $4 \mathrm{~cm}$, which was chosen based on the smallest dimension of the bricks and which is sufficiently large as stated by Feng and Janssen [24]. 


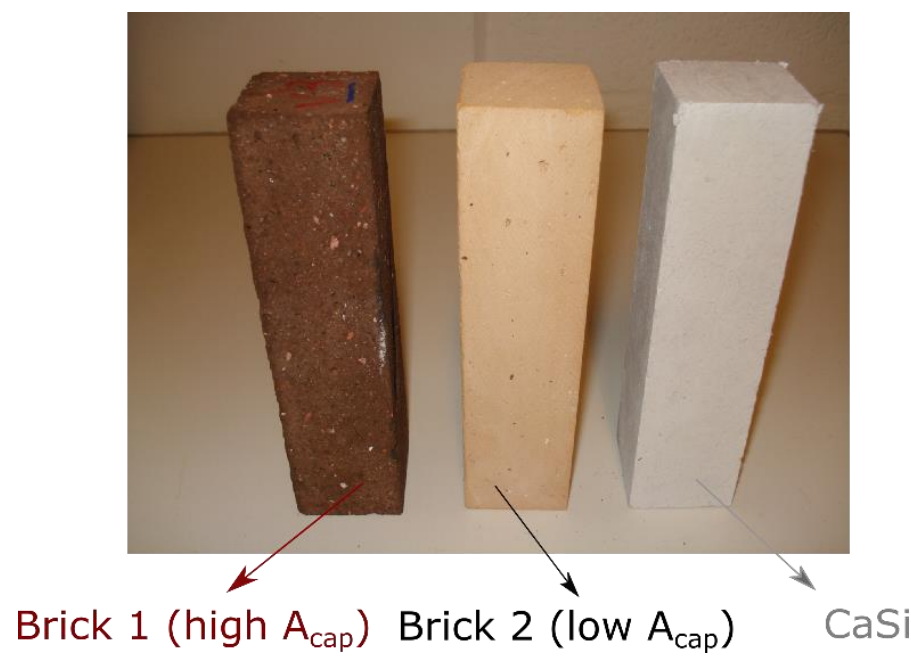

Figure 1. Different types of test materials: high absorptive brick (left), low absorptive brick (middle) an high absorptive calcium silicate (right).

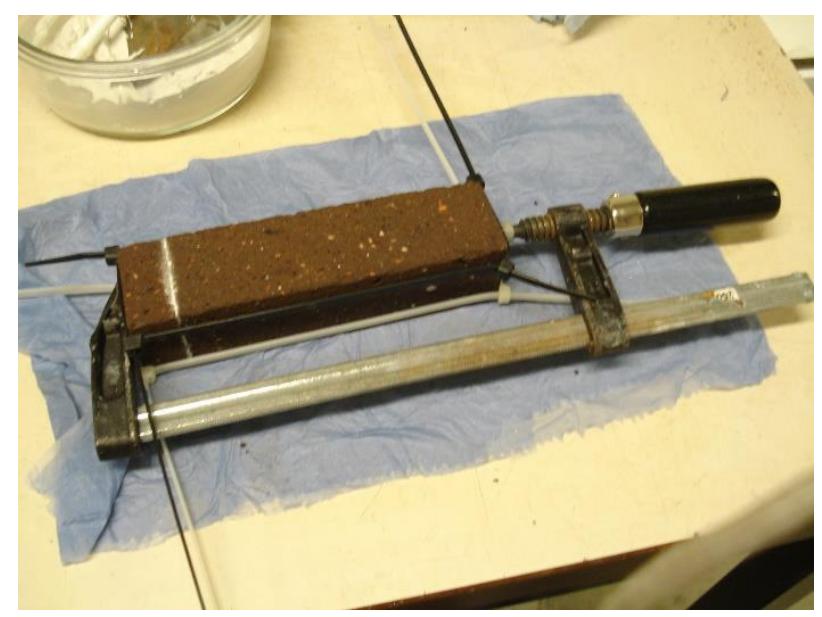

Figure 2. Preparation of the composite samples by use of kaolin clay: one of the composite samples with clamping screws and cable ties. 
Table 1. Height of the bottom and the top sample for the different test samples.

\begin{tabular}{ccc}
\hline Sample & Height bottom sample $(\mathrm{cm})$ & Height top sample $(\mathrm{cm})$ \\
\hline 1,2 & 2 & 14 \\
3,4 & 4 & 12 \\
5,6 & 6 & 10 \\
7,8 & 8 & 8 \\
9,10 & 10 & 6 \\
11,12 & 12 & 4 \\
13,14 & 14 & 2 \\
M1, M2 & 16 & $/$ \\
\hline
\end{tabular}

\subsubsection{Material properties}

As mentioned in Section 2.2.1, three series of test samples were studied in order to analyse a potential impact of the material properties. An overview of the basic hygric properties for the three different materials is given in Table 2. An important difference in material properties can be observed based on the capillary absorption coefficient, which is high for Brick 1 and even higher for calcium silicate, while moderate for Brick 2. Additionally, the moisture storage properties differ. The capillary moisture content of the calcium silicate is much higher than for both bricks. The moisture retention curve and the moisture permeability curve are shown in Figure $3 a$ and $b$, respectively. Furthermore, Figure $3 c$ shows the materials' pore volume distribution. The higher capillary absorption coefficient of Brick 1 corresponds to the larger (relative) share of coarse pores for this brick, while in case of calcium silicate the much higher porosity 
and higher permeability in the mid-saturation range yields a higher capillary absorption coefficient.

Table 2. Basic hygric material properties.

\begin{tabular}{cccc}
\hline & $\begin{array}{c}\text { Brick 1 } \\
\text { (high absorptive) } \\
{[22,24]}\end{array}$ & $\begin{array}{c}\text { Brick 2 } \\
\text { (low absorptive) } \\
{[25]}\end{array}$ & $\begin{array}{c}\text { Calcium silicate } \\
\text { (high absorptive) } \\
\text { [24], in-house } \\
\text { measurements) }\end{array}$ \\
\hline$\rho_{\mathrm{b}}\left(\mathrm{kg} / \mathrm{m}^{3}\right)$ & 1818 & 1549 & 278 \\
Open porosity (\%) & 32.6 & 41.3 & 89.2 \\
$\mathrm{w}_{\text {cap }}\left(\mathrm{kg} / \mathrm{m}^{3}\right)$ & 210 & 256 & 795 \\
$\mathrm{w}\left(\mathrm{p}_{\mathrm{c}}\right)$ & Figure $3 a$ & Figure 3a & Figure $3 a$ \\
$\mu_{\text {dry }}(-)$ & 11.6 & 14.6 & 1.97 \\
$\mathrm{~K}_{\mathrm{l}}(\mathrm{s})$ & Figure $3 b$ & Figure $3 b$ & Figure $3 b$ \\
$\mathrm{~A}_{\text {cap }}\left(\mathrm{kg} /\left(\mathrm{m}^{2} \mathrm{~s}^{0.5}\right)\right)$ & 0.61 & 0.26 & 1.28 \\
\hline
\end{tabular}


— Brick 1 (high $\left.A_{\text {cap }}\right)-$ Brick $2\left(\right.$ low $\left.A_{\text {cap }}\right)-$ CaSi

a)

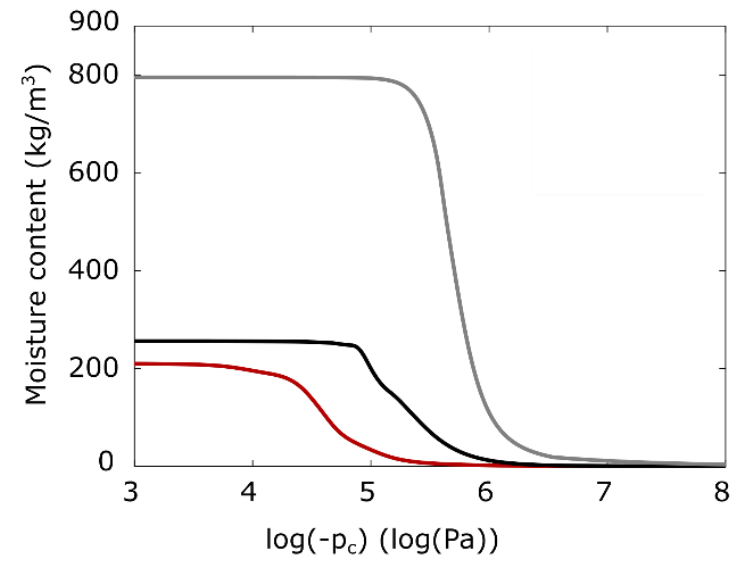

b)

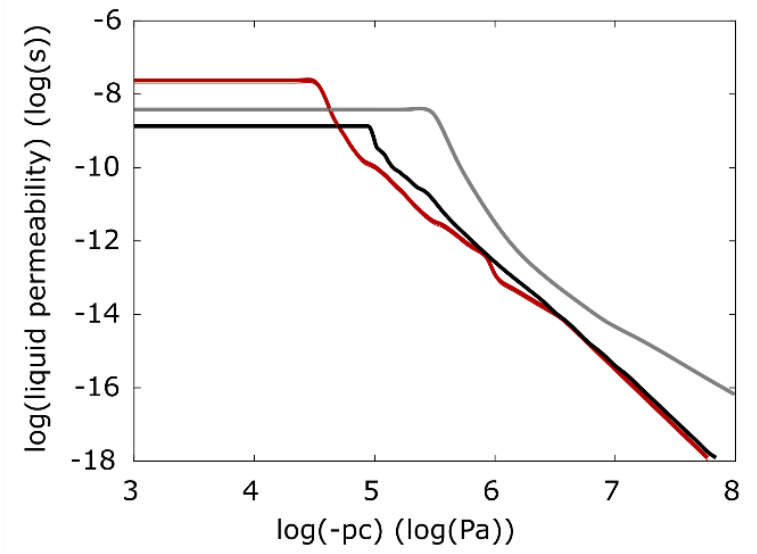

c)

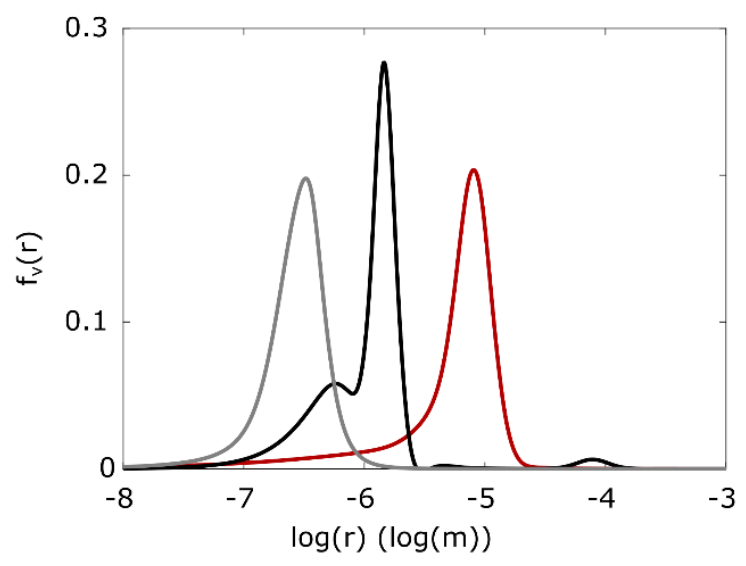

Figure 3. (a) Moisture retention curve starting from $\mathbf{w}_{\text {cap }}$, (b) moisture permeability curve and (c) pore volume distribution for the three materials. 


\subsection{Imbibition test setup}

The presence of a hydraulic interface resistance is analysed by comparing the water uptake curves of monolithic and composite samples measured during an imbibition experiment (Figure 4). The samples were initially oven-dried at $50^{\circ} \mathrm{C}$, before which they were conditioned at $50 \%$ relative humidity in order to avoid a too fast drying of the moist kaolin clay. Before starting the imbibition experiments, in order to facilitate the measurements, the clamping screws were gently removed, while the cable ties were kept around the samples in order to keep a good contact between both specimen. This approach was justified as a single measurement on a composite sample hold together with clamping screws showed a similar behaviour as found for a composite sample hold together with the cable ties only. To provide identical conditions for the composite and monolithic samples, these cable ties were also put around the monolithic samples. Though, also here, a single experiment on a monolithic sample without cable ties showed no difference and thus no impact of the cable ties. The samples were supported by thin plastic bars and were brought in contact with a water plain. Moisture transport was thus possible via the samples' bottom surface. The water level was maintained at approximately $1 \mathrm{~mm}$ above the basis of the samples. The free surfaces of the samples were not wrapped with foil, thus surface evaporation might have taken place. Though, this phenomenon will not influence the general findings and final conclusions of the current study. 


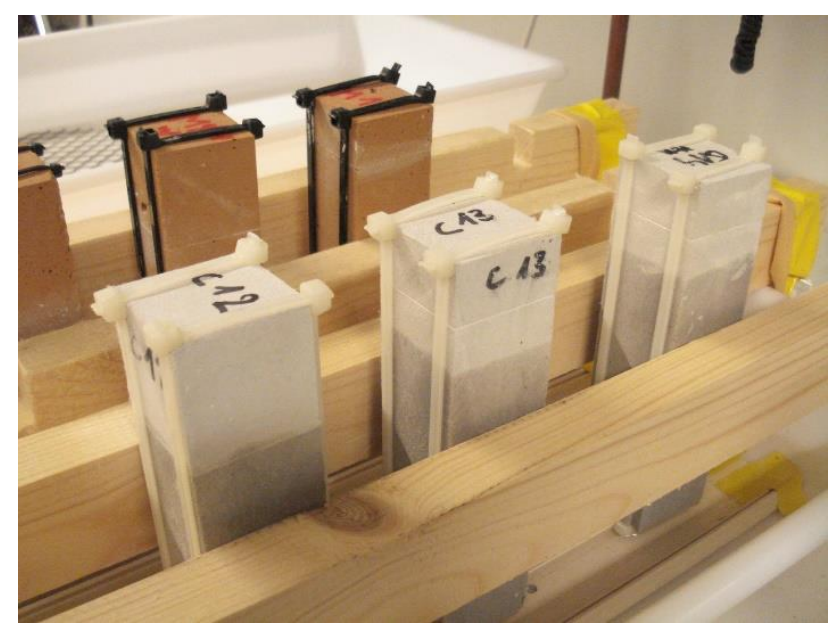

Figure 4. Imbibition experiment on a selection of the test samples. Bars were positioned next to the samples (without contact between test samples and bars) to avoid the samples falling in the water in case of instability.

\subsection{Interface resistance assessment}

To assess the presence and impact of a hydraulic interface resistance between the specimen, the imbibition experiments are numerically simulated and the numerical output is compared to the experimental results. In the current study, the numerical simulations are performed by use of Delphin 5 , a control volume model to solve heat and moisture transport in building materials [26]. Between both specimen, a control volume with a thickness of $1 \mu \mathrm{m}$ is implemented. The moisture flow $g_{I F}\left(\mathrm{~kg} /\left(\mathrm{m}^{2} \mathrm{~s}\right)\right)$ across the interface is simulated as $[9,19]$ :

$$
g_{I F}=K_{I F} \cdot \frac{\partial p_{c}}{\partial x}=\frac{\Delta p_{c}}{\frac{1}{K_{I F}} \cdot \Delta x}=\frac{\Delta p_{c}}{R_{I F}}
$$

where $\Delta p_{c}$ is the discontinuity in capillary pressure across the interface ( $\left.\mathrm{Pa}\right), \Delta x$ is the thickness of the control volume applied to implement the interface (in this case $1 \cdot 10^{-6}$ 
$\mathrm{m}), K_{I F}$ is a fictitious interface permeability $(\mathrm{s})$ and $R_{I F}$ is the interface resistance $(\mathrm{m} / \mathrm{s})$. Thus, to simulate the potential interface resistance, the control volume implemented to simulate the interface is given a (compared to the test material's moisture permeability) reduced moisture permeability $K_{I F}(\mathrm{~s})$, which is linked to the interface resistance $R_{I F}$ $(\mathrm{m} / \mathrm{s})$ by:

$$
K_{I F}=\frac{\Delta x}{R_{I F}}
$$

In the current study, the moisture permeability of the interface layer $\left(K_{I F}\right)$ is an unknown parameter that is modified in the simulations until a good agreement between experimental and numerical output is found. As the value of the appropriate moisture permeability $K_{I F}$ is co-determined by the thickness $\Delta x$ of the interface control volume applied in the numerical simulations, in Section 3 no values for $K_{I F}$ will be given. Instead, the results of the interface resistance $R_{I F}$, which is independent of the control volume thickness, will be given. At this stage, the interface resistance is assumed to be constant, and thus a potential capillary pressure or moisture content dependency of the interface resistance is neglected. The other properties of the interface control volume are set equal to the specimen's properties, which gives the interface layer no hygroscopic capacity. 


\section{Results}

\subsection{Experimental output}

Figure 5 shows the water uptake curves for the three types of samples. For the high absorptive bricks (Figure 5a) and the high absorptive calcium silicate (Figure $5 \mathrm{c}$ ), the curves measured for the composite samples are slightly till largely different from the results found for the monolithic samples. A reduction of the slope occurs when the moisture reaches the contact interface between both specimen. The largest deviation is observed for the samples with the lowest distance between the contact interface and the water plain. This retardation of the water uptake process indicates the presence of an imperfect hydraulic contact between the high absorptive brick specimen and between the calcium silicate specimen. If the contact interface is at a lager distance from the water plain, i.e. for Samples 13 and 14 with a distance of $14 \mathrm{~cm}$ between the contact interface and the water plain, the impact of the imperfect interface contact is less or not pronounced.

The water uptake curves measured for the low absorptive brick composites (Figure 5b), on the other hand, show a good agreement with the curves measured for the monolithic samples. Hence, for this type of material no hydraulic interface is present, or, if present, it has no impact on the water uptake curve. Small deviations between the different curves, such as for instance found between Sample 9 and the monolithic sample, can be attributed to small differences between the brick samples, which can be confirmed by the random order of the curves. 


$$
\begin{array}{llll}
-\diamond-1,2 & -\diamond-3,4 & -\diamond-5,6 & -\diamond-7,8 \\
-\diamond-9,10 & -\diamond-11,12 & -\diamond-13,14 & \rightarrow-M 1, M 2
\end{array}
$$

a)

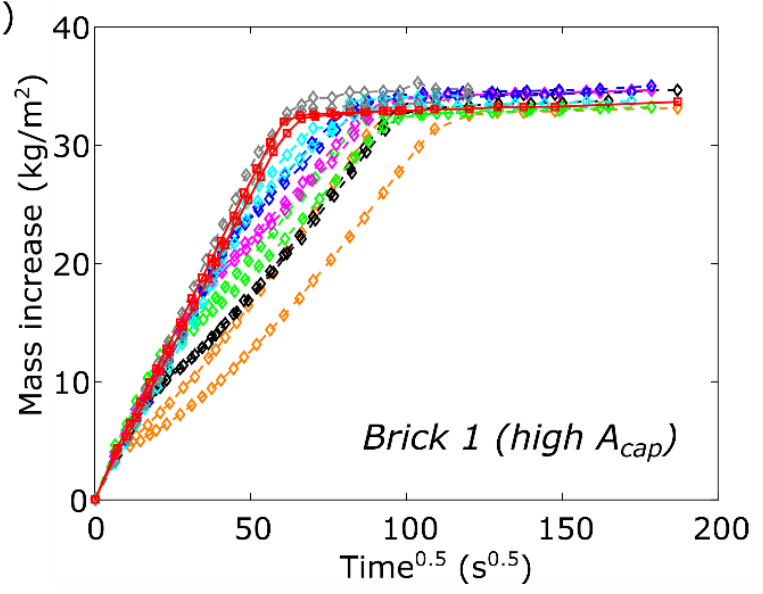

b)

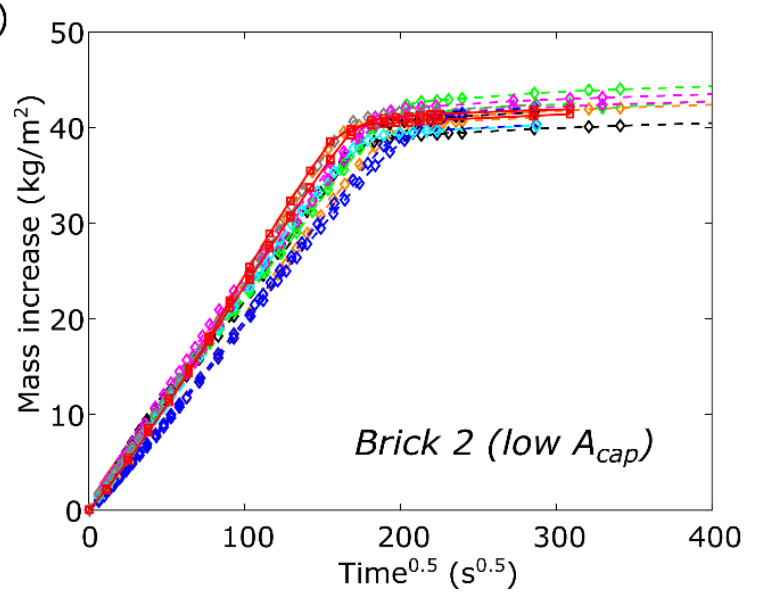

C) 140

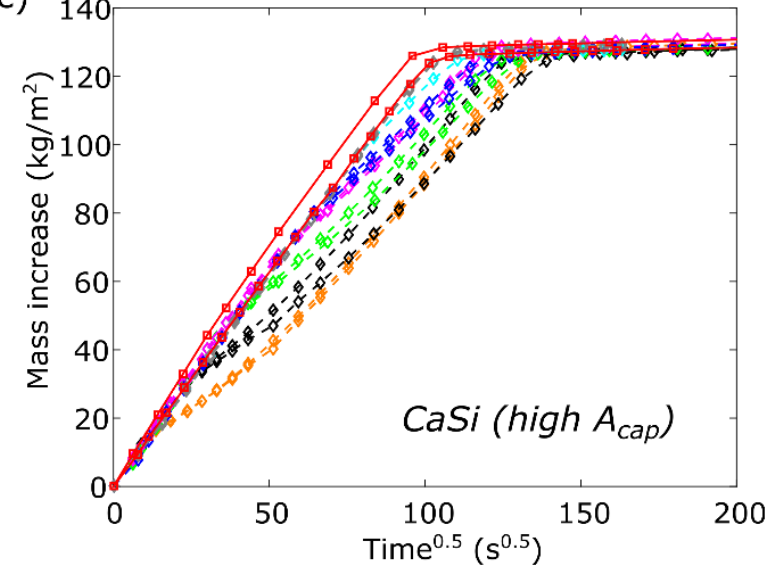

Figure 5. Experimental water uptake curve for (a) high absorptive brick, (b) low absorptive brick, (c) high absorptive calcium silicate. 


\subsection{Hydraulic interface resistance assessment}

\subsubsection{High absorptive brick}

A comparison between the numerical and experimental findings for the samples composed of high absorptive bricks is shown in Figure 6 . As a reference, in Figure 6a first the numerical and experimental water uptake curve for the monolithic samples are compared. A good agreement is found. For the composite samples, an interface resistance $R_{I F}$ should be numerically implemented to model the retardation of the moisture transport. The impact of the distance between water plain and interface contact on this interface resistance is analysed, as shown in Figure 6b till Figure 6h. For each case, a series of numerical simulations, each of them with a different $R_{I F-}$ value, is performed and the numerically simulated water uptake curves are compared

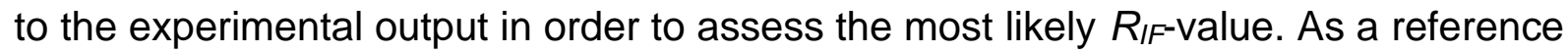
and to indicate the impact of the interface resistance more clearly, furthermore, the water uptake curve in absence of an interface $\left(R_{I F}=0 \mathrm{~m} / \mathrm{s}\right.$, as for the monolithic sample) is shown. For the samples with an interface contact at $2 \mathrm{~cm}$ from the water plain (Figure 6b), a small difference between the experimental output achieved for both test samples can be observed. The highest of both water uptake curves showed a reasonable agreement when using a an interface resistance $R_{\text {IF }}$ of $6000 \mathrm{~m} / \mathrm{s}$, while the lowest of both curves showed a good agreement for an interface resistance of $12000 \mathrm{~m} / \mathrm{s}$. This order of magnitude for the interface resistance yields furthermore a good agreement between the experimental and numerical results achieved for the test samples with a larger distance between the contact interface and the water plain 
(Figure 6c-h). Moreover, the deviation between the curves achieved for each of both

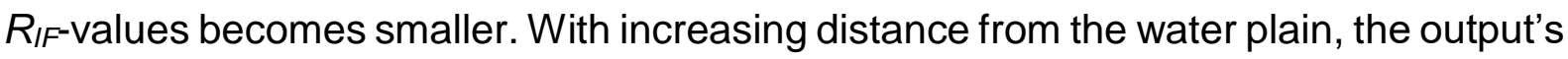
sensitivity to the implemented $\underline{R_{\mathbb{F}}-v a l u e ~ d i m i n i s h e s . ~ F o r ~ t h e ~ c o m p o s i t e ~ s a m p l e ~ w i t h ~ a ~}$ contact interface at a distance of $14 \mathrm{~cm}$ from the water plain (Figure 6h), the experimental curve furthermore coincides with the numerical curve achieved without an interface resistance. Even when implementing an interface resistance approximately ten times higher $\left(R_{I F}=100000 \mathrm{~m} / \mathrm{s}\right)$, the numerically simulated water uptake curve is still in reasonable agreement. For all other samples, though, such interface resistance clearly results in an underestimation of the water uptake curve. 
- Measurement data $\quad--R_{I F}=0 \mathrm{~m} / \mathrm{s} \quad-R_{I F}=6000 \mathrm{~m} / \mathrm{s}$

a)

a)
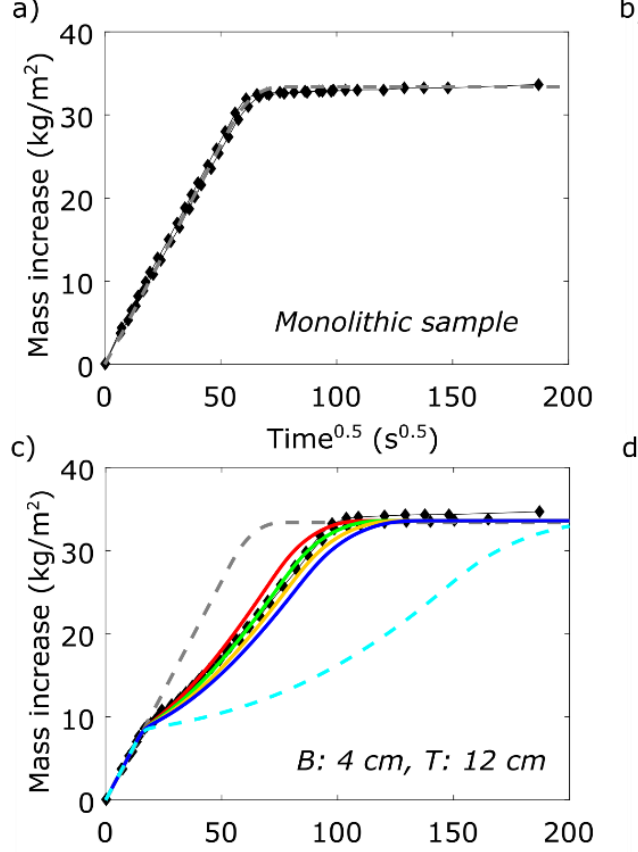

e) $\operatorname{Time}^{0.5}\left(s^{0.5}\right)$

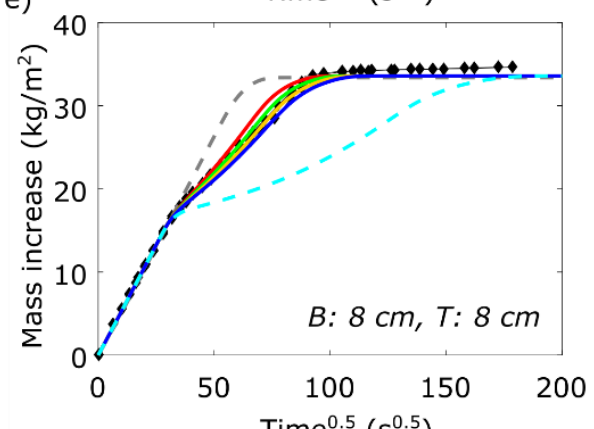

g)

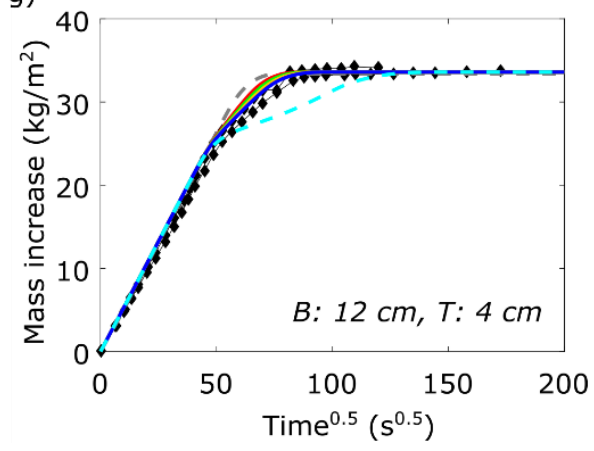

b)

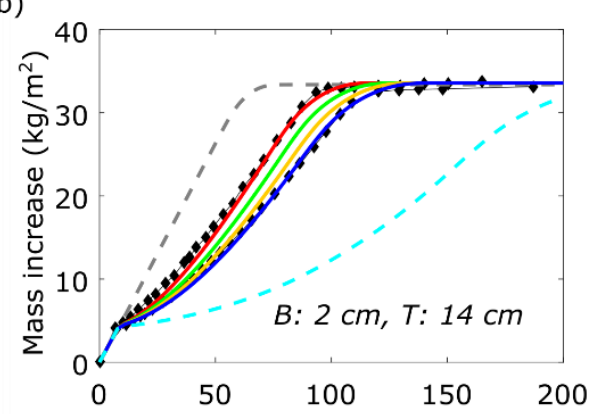

d)

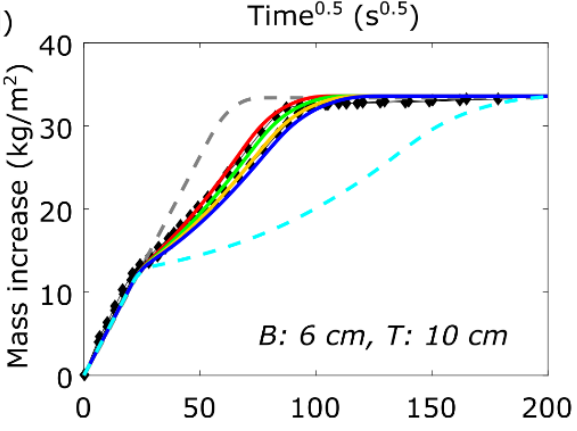

f) $\quad \operatorname{Time}^{0.5}\left(\mathrm{~s}^{0.5}\right)$

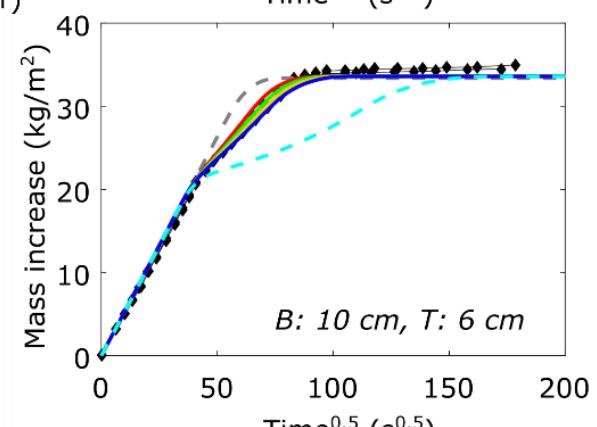

h)

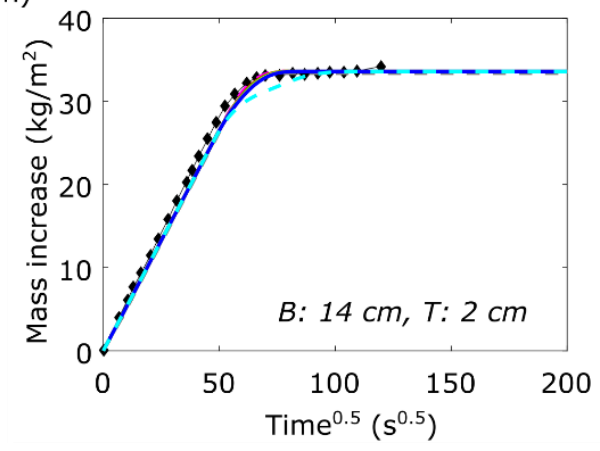

Figure 6. Comparison between experimentally and numerically simulated water uptake curve for a high absorptive brick: (a) monolithic sample, (b-h): composite samples with a different distance between water plain and contact interface. For the composite samples, the impact of the interface resistance $R_{I F}$ is shown. 
3.2.2. High absorptive calcium silicate

To further analyse the material dependency, Figure 7 shows similar graphs for calcium silicate. As a reference, Figure $7 a$ shows the results of the monolithic samples, for which, based on the material properties given in Section 2.2.2, a good agreement is found. Next, Figure $7 b-h$ show the results for the composite samples. Similarly as for the high absorptive brick composite samples discussed in Section 3.2.1, the hydraulic interface resistance is studied for a series of distances between the contact interface and the water plain. A good agreement is obtained when implementing an $R_{\mathbb{I F} \text {-value of }}$ $25000 \mathrm{~m} / \mathrm{s}$, and this again regardless of the distance between contact interface and

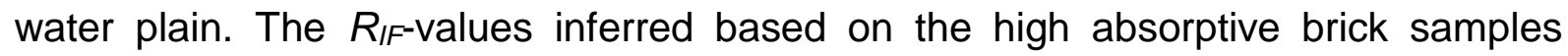
(Section 3.2.1) result in an overestimation of the water uptake rate. Again, for a larger distance between contact interface and water plain, the water uptake curve becomes less sensitive to the hydraulic interface resistance. 

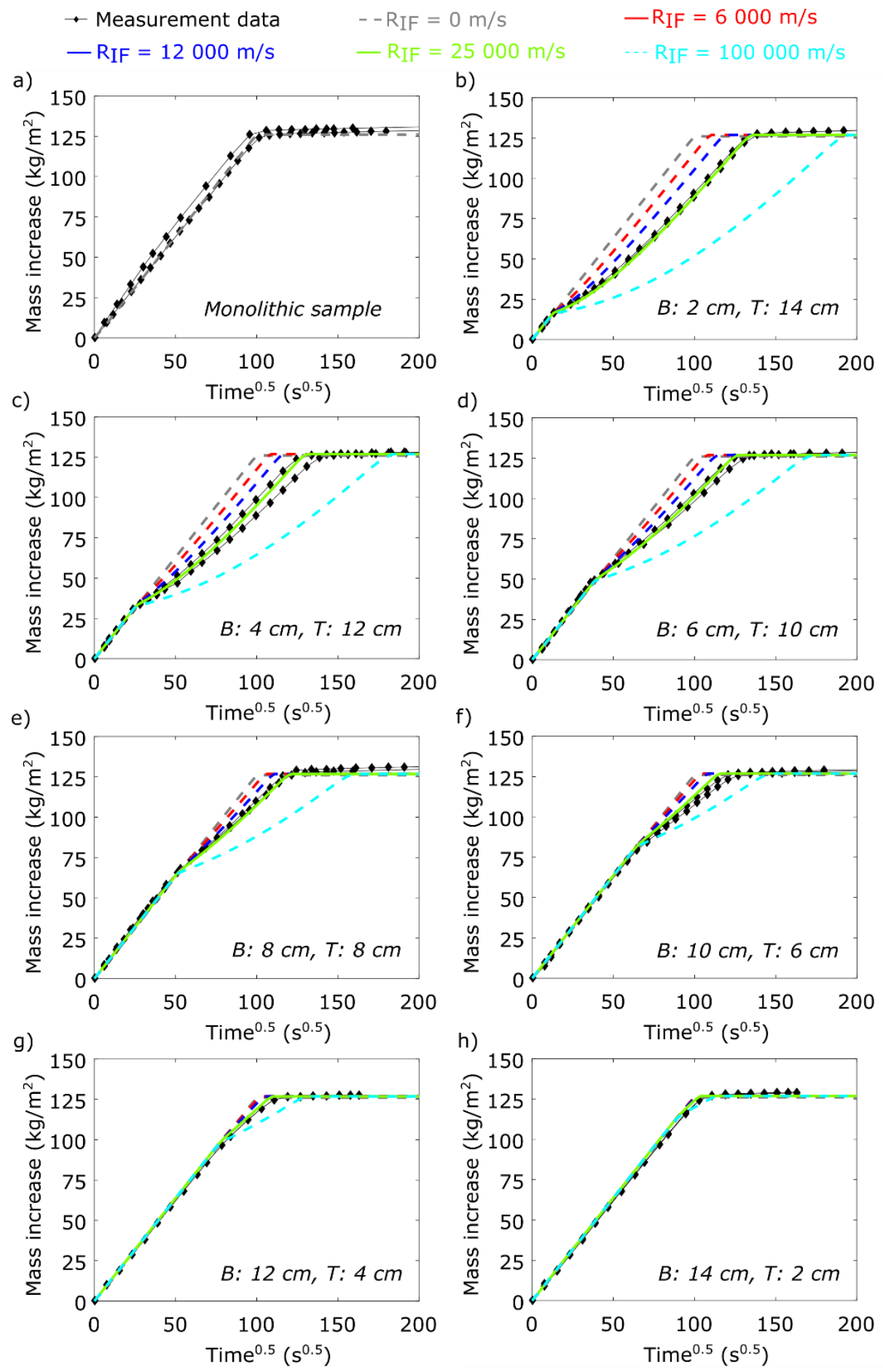

Figure 7. Comparison between experimentally and numerically simulated water uptake curves for a (high absorptive) calcium silicate: (a) monolithic sample, (bh): composite samples with a different distance between water plain and contact 
interface. For the composite samples, the impact of the interface resistance $R_{I F}$ is shown.

\subsubsection{Low absorptive brick}

As shown in Section 3.1, for the low absorptive brick, the composite samples show a similar water uptake curve as measured for the monolithic samples. Therefore, the experimentally measured water uptake curves are shown only for the two composite test samples with the interface closest to the water plane, i.e. Sample 1 and Sample 2. As for the previous materials, first the water uptake curve without an interface resistance was simulated. Based on the 'Brick 2' properties given in Section 2.2.2, a good agreement with Sample 1 was achieved (Figure 8a). Next, the impact of an interface resistance is studied based on numerical simulations of the low absorptive brick composite samples with a distance of $2 \mathrm{~cm}$ between the contact interface and the water plain (Figure 8b). After all, as indicated before, the smaller the distance between contact interface and water plain, the higher the sensitivity of the water uptake to the interface resistance. The implementation of an interface resistance $R_{I F}$ in the order of magnitude as estimated for the high absorptive brick ( $R_{I F}$ between $6000 \mathrm{~m} / \mathrm{s}$ and $12000 \mathrm{~m} / \mathrm{s}$ ) has only a negligible impact on the water uptake curve. Hence, a similar water uptake curve for composite and monolithic samples does not prove the complete absence of an interface resistance between the materials. For $R_{I F}=25000 \mathrm{~m} / \mathrm{s}$, the curve falls close to the curve of Sample 2. Though, for the latter case a slight overestimation of the initial water uptake (inset in Figure $8 b$ ), and hence of the brick's 
capillary absorptivity is made. The larger $R_{I F}$-value is thus a consequence of the underestimation of the brick's hydraulic resistance that has to be compensated. Finally, for completeness and as a comparison with Figure 6 and Figure 7, the impact of $R_{I F}=$ $100000 \mathrm{~m} / \mathrm{s}$ is shown and is found to be clearly pronounced.

- Measurement data

- RIF $=12000 \mathrm{~m} / \mathrm{s}$

a)

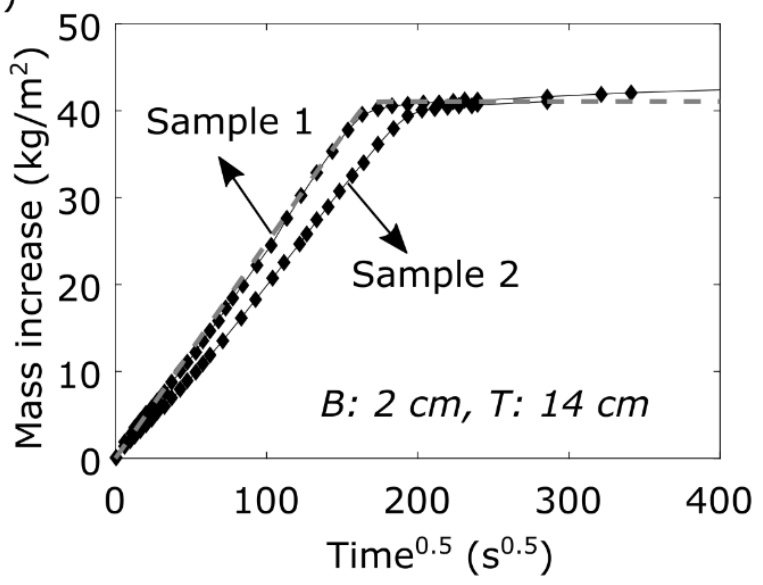

-- RIF $=0 \mathrm{~m} / \mathrm{s}$

- RIF $=25000 \mathrm{~m} / \mathrm{s}$

b)

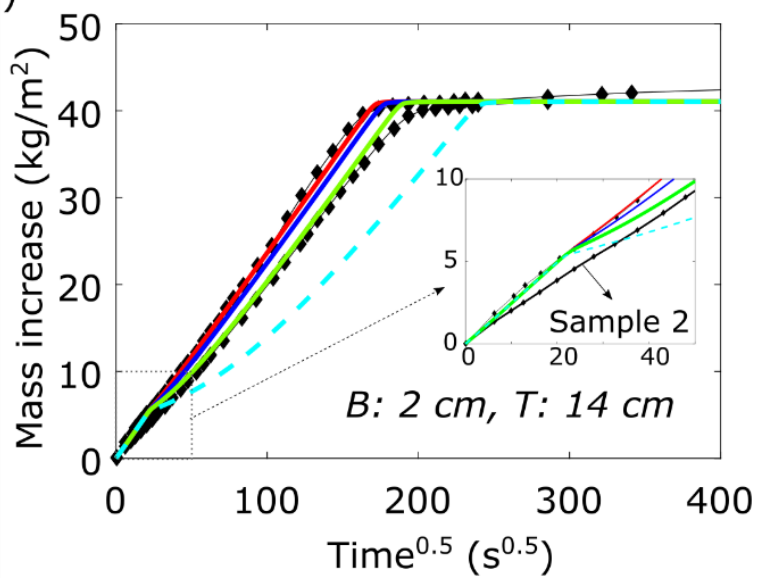

Figure 8. Comparison between experimentally and numerically simulated water uptake curve for a low absorptive brick: (a) without interface resistance, (b) with interface resistance.

\section{Discussion}

\subsection{Effectiveness as a function of the specimen's $A_{\text {cap }}$}

Based on the experimental results achieved in the current study, a kaolin layer in between low absorptive specimen (Brick 2 with $A_{c a p} \leq 0.26 \mathrm{~kg} /\left(\mathrm{m}^{2} \mathrm{~s}^{0.5}\right)$ ) was shown to 
have no impact on the water uptake curve. This behaviour was also found by Holm et al. [21], who specified the capability of kaolin clay to provide an ideal hygric contact, and this based on a water uptake curve measured for a sample composed of two Rüthener sandstone specimen with $A_{c a p}$ between 0.21 and $0.255 \mathrm{~kg} /\left(\mathrm{m}^{2} \mathrm{~s}^{0.5}\right)$. Also the other material specimen used in their study on moisture transport across material interfaces were characterized by a low $A_{\text {cap }}$ (in the range of 0.025 and 0.225 $\left.\mathrm{kg} /\left(\mathrm{m}^{2} \mathrm{~s}^{0.5}\right)\right)$. This way, the kaolin clay layer is expected to have no impact on the work presented by Holm et al. [21]. It should however be stressed that the findings were obtained based on the total cumulative moisture inflow. The measurements and simulations in this study revealed that a hydraulic interface resistance is probably present, but without any impact on the cumulative inflow. Proving this statement would require a more in depth analysis of the moisture profiles in the test samples during the uptake experiments.

In case of materials with a higher Acap, the current study clearly revealed that kaolin clay is inadequate for the creation of a perfect hydraulic contact. A distinct deviation of the cumulative inflow was observed for the composite specimen compared to the monolithic specimen in the experiments on materials with $A_{\text {cap }} \geq 0.61 \mathrm{~kg} /\left(\mathrm{m}^{2} \mathrm{~s}^{0.5}\right)$. In this respect, a reference could be made to the water uptake experiments on multilayered samples composed of brick, glue mortar and calcium silicate described in [27]. For the test samples composed by use of kaolin clay, the numerical simulations did not fully coincide with the experimental data. Possible reasons for this, enumerated in [27], were amongst others the creation of a small interface resistance during the preparation process and a small deviation of the glue mortar properties. Similarly, in [28] kaolin 
clay did not provide an ideal hydraulic contact between a brick $\left(A_{c a p}=0.107 \mathrm{~kg} /\left(\mathrm{m}^{2} \mathrm{~s}^{0.5}\right)\right)$ and a mould cured mortar $\left(A_{\text {cap }}=0.343 \mathrm{~kg} /\left(\mathrm{m}^{2} \mathrm{~s}^{0.5}\right)\right)$. Also here, small cracks in the kaolin clay due to manipulation after curing was put forward as a possible reason. Based on the knowledge achieved in the current paper, however, the deviation between experimental and numerical outcome could be (partially) attributed to the noneffectiveness of kaolin clay in providing a perfect hydraulic contact for the respective materials.

To what extent the kaolin layer has an impact on the water transport depends on amongst others the specimens' absorptivity, as shown by the experiments on different types of materials. Note however that the authors have no intention to specify a single

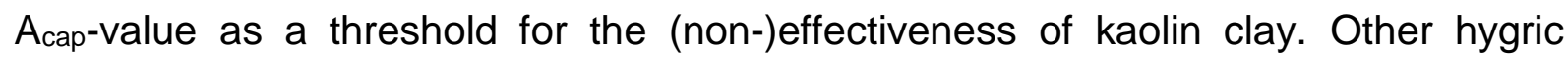
properties, achieved as a result of the material's pore structure, will co-determine to what extent the kaolin clay will be effective in the creation of a perfect hydraulic contact.

\subsection{Order of magnitude of $R_{I F}$}

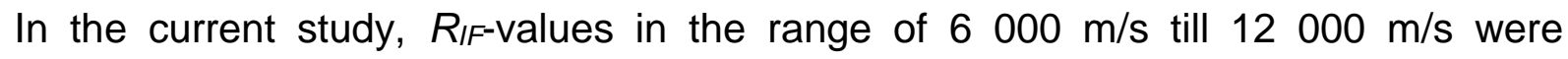
determined for the high absorptive brick and of $25000 \mathrm{~m} / \mathrm{s}$ for the calcium silicate.

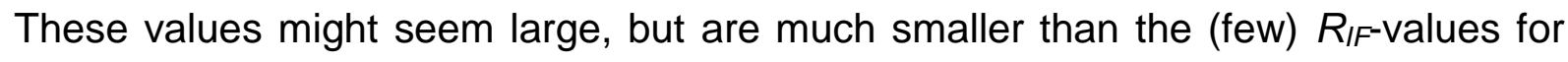
actual brick-mortar interfaces presented in the literature $[19,28,29]$. For instance, Derluyn et al. [19] inferred a hydraulic interface resistance of $1.25 \times 10^{10} \mathrm{~m} / \mathrm{s}$ between a brick (with $A_{c a p}=0.116 \mathrm{~kg} /\left(\mathrm{m}^{2} \mathrm{~s}^{0.5}\right)$ ) and a wet cured mortar $\left(A_{\text {cap }}=0.015 \mathrm{~kg} /\left(\mathrm{m}^{2} \mathrm{~s}^{0.5}\right)\right.$ ) and of $2.5 \times 10^{10} \mathrm{~m} / \mathrm{s}$ between the same brick and a dry cured mortar ( $A_{\text {cap }}=0.010$ $\left.\mathrm{kg} /\left(\mathrm{m}^{2} \mathrm{~s}^{0.5}\right)\right)$. 


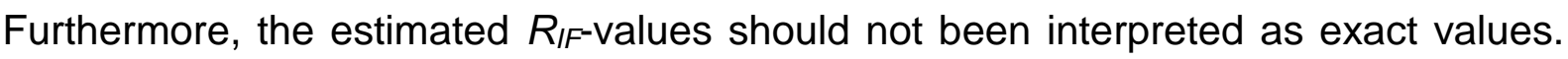
Small deviations on the experimental data can result in a reduplication of the $R_{I F-v a l u e}$ as proven by the brick measurements. Additionally, small deviations on the specimen's moisture properties applied in the numerical simulations will influence the estimated

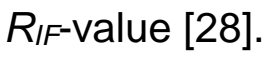

\subsection{Constant interface resistance}

As mentioned in Section 2.4, in the current study, the estimated interface resistance is assumed to be a constant; and this while some studies state the interface resistance to be possibly dependent on capillary pressure or moisture content $[9,27,28,29]$. A further study on this dependency, based on for instance moisture profile measurements, is required.

\section{Conclusions}

This paper verified, based on a series of imbibition experiments, the common assumption that kaolin clay is able to provide a perfect hydraulic contact between materials. For high absorptive materials, when using kaolin clay, an imperfect hydraulic contact was found to be present. In case of high absorptive bricks $\left(A_{c a p}=0.61\right.$ $\left.\mathrm{kg} /\left(\mathrm{m}^{2} \mathrm{~s}^{0.5}\right)\right)$, a hydraulic interface resistance between $6000 \mathrm{~m} / \mathrm{s}$ and $12000 \mathrm{~m} / \mathrm{s}$ revealed to result in a good agreement with the experimentally measured water uptake curves. For calcium silicate $\left(A_{c a p}=1.28 \mathrm{~kg} /\left(\mathrm{m}^{2} \mathrm{~s}^{0.5}\right)\right)$, this interface resistance had to be increased to $25000 \mathrm{~m} / \mathrm{s}$ to coincide with the experimental data. In both cases, a single

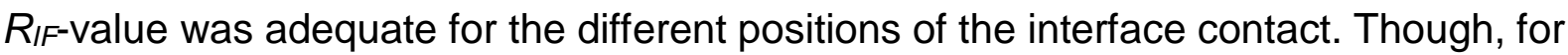


a larger distance between contact interface and water plain, the impact of the interface

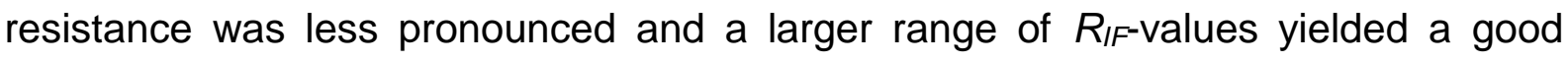
agreement between simulated and measured water uptake curves. A more distinct impact was observed in case of a small distance between contact interface and water plain. Hence, a precise determination of the hydraulic interface resistance benefits from experiments on samples with a contact interface close to the water plain in case of a determination based on water uptake curves and/or of an analysis of the moisture profiles in the composite sample. For low absorptive bricks, the water uptake curves of the composite samples prepared by use of kaolin clay coincided with the curves achieved for the monolithic samples. Though, the water uptake curves were less sensitive to the implementation of a hydraulic interface resistance. Hence, also in this case, the kaolin layer probably creates a hydraulic interface resistance, but the resistance is too low to be noticeable in the cumulative inflow.

\section{Acknowledgements}

Evy Vereecken is a postdoctoral fellow of the Research Foundation (FWO) - Flanders, Belgium (FWO project 12J5219N). This financial support is gratefully acknowledged.

\section{References}

[1] Vereecken E, Van Gelder L, Janssen H, Roels S. 2015. Interior insulation for wall retrofitting - A probabilistic analysis of energy savings and hygrothermal risks. Energy Build 89:231-244. https://doi.org/10.1016/j.enbuild.2014.12.031 
[2] Zhao J, Grunewald J, Ruisinger U, Feng S. 2017. Evaluation of capillary-active mineral insulation systems for interior retrofit solution. Build Environ 115:215227. https://doi.org/10.1016/j.buildenv.2017.01.004

[3] Zhou X, Derome D, Carmeliet J. 2017. Hygrothermal modeling and evaluation of freeze-thaw damage risk of masonry walls retrofitted with internal insulation. Build Environ 2017;125:285-298.

https://doi.org/10.1016/..buildenv.2017.08.001

[4] Van Roy N, Verstrynge E, Janssen H, Vereecken E, Van Balen K. 2018. Feasibility analysis of the simulation of the physical durability of joint repair for traditional brick masonry. $10^{\text {th }}$ International Masonry Conference, Milan, Italy, July 9-11, 1698-1708.

[5] Mendes N, Philippi P. 2005. A method for predicting heat and moisture transfer through multi-layered walls based on temperature and moisture content gradients. Int $\mathrm{J}$ Heat Mass Transf 48:37-51. https://doi.org/10.1016/j.ijheatmasstransfer.2004.08.011

[6] Groot C. 1995. Effects of water on mortar-brick bond. Heron 40:57-70.

[7] Brocken H. 1998. Moisture transfer in brick masonry: the grey area between bricks. PhD Thesis, TU Eindhoven, The Netherlands.

[8] Brocken H, Spiekman M, Pel L, Kopinga K, Larbi J. 1998. A water extraction out of mortar during brick laying: a NMR study. Mater Struct 31:49-57.

[9] Qiu X, Haghighat F, Kumaran K. 2003. Moisture transport across interfaces between autoclaved aerated concrete and mortar. Journal of Thermal Env. Bldg. Sci. 26:213-236. https://doi.org/10.1177/109719603032804 
[10] Janssen H, Derluyn H, Carmeliet C. 2012. Moisture transfer through mortar joints: A sharp-front analysis. Cement Concrete Res 42:1105-1112. https://doi.org/10.1016/i.cemconres.2012.05.004

[11] Guimarães A, Delgado J, Azevedo A, de Freitas V. 2018. Interface influence on moisture transport in buildings. Constr Build Mater 162:480-488. https://doi.org/10.1016/i.conbuildmat.2017.12.040

[12] Janssen H. 2020. A critique on characterizing interface resistances with maximum moisture flows. Constr Build Mater 243:118301. https://doi.org/10.1016/i.conbuildmat.2020.118301

[13] Nunes C, PEI L, Kunecký J, Sližková. 2017. The influence of the pore structure on the moisture transport in lime plaster-brick systems as studied by NMR. $\begin{array}{llll}\text { Constr } & \text { Build } & \text { 142:395-409. }\end{array}$ https://doi.org/10.1016/i.conbuildmat.2017.03.086

[14] Tran Le A, Maalouf C, Mendonça K, Wurtz E. 2009. Study of moisture transfer in a double-layered wall with imperfect thermal and hydraulic contact resistances. J Build Perform Simul 251-266. https://doi.org/10.1080/19401490903082459

[15] Vereecken E, Roels S. 2013. Hygric performance of a massive masonry wall: How do the mortar joints influence the moisture flux? Constr Build Mater 41:697707. https://doi.org/10.1016/j.conbuildmat.2012.12.024 
[16] Delgado J, Azevedo A, Guimarães A. 2020. Influence on hydraulic contact on drying process of masonry walls. Dry Technol 38(9):1121-1137. https://doi.org/10.1080/07373937.2019.1615939

[17] De Freitas VP, Abrantes V, Crausse P. 1996. Moisture migration in building walls: analysis of the interface phenomena. Build Environ 31(2):99-108. https://doi.org/10.1016/0360-1323(95)00027-5

[18] Depraetere W, Carmeliet J, Hens H. 2000. Moisture transfer at interfaces of porous materials: measurements and simulations, PRO 12: International RILEM Workshop on Historic Mortars: Characteristics and Tests, University of Paisley, Scotland, 12th-14th May, p.249-259.

[19] Derluyn H, Janssen H, Carmeliet J. 2011. Influence of the nature of interfaces on the capillary transport in layered materials. Constr Build Mater 25:3685-3693. https://doi.org/10.1016/i.conbuildmat.2011.03.063

[20] Vereecken E, Roels S. 2014. A numerical study of the influence of the hydraulic interface contact on the hygric performance of a multi-layered system. In: XIII International Conference on Durability of Building Materials and Components, Sao Paulo, 2-5 September 2014: 512-519.

[21] Holm A, Krus M, Künzel H. 1996. Feuchtetransport über Materialgrenzen im Mauerwerk. International Zeitschrift für Bauinstandsetzen, 2. Jahrgang, Heft 5.

[22] Soulios V, de Place Hansen E, Janssen H. 2019. Hygric properties of hydrophobized building materials. Matec Web of Conferences 282, 02048, CESBP2019. https://doi.org/10.1051/matecconf/201928202048 
[23] Voronina V. 2011. Salt extraction by poulticing: an NMR study. PhD Thesis, TU Eindhoven, The Netherlands

[24] Feng C, Janssen H. 2018. Hygric properties of porous building materials (III): Impact factors and data processing methods of the capillary absorption test. Build Environ 134:21-34. https://doi.org/10.1016/..buildenv.2018.02.038

[25] Vanpachtenbeke M. 2019. Timber frame walls with brick veneer claddings. PhD Thesis, KU Leuven, Belgium.

[26] Delphin 5. 2006. Simulation program for the calculation of coupled heat, moisture, air, pollutant and salt transport. Institut für Bauklimatik, TU Dresden. http://bauklimatik-dresden.de/delphin/index.php?aLa=en

[27] Vereecken E. 2013. Hygrothermal analysis of interior insulation for renovation projects. PhD Thesis, KU Leuven, Belgium.

[28] Calle K, De Kock T, Cnudde V, Van den Bossche N. 2019. Liquid moisture transport in combined ceramic brick and natural hydraulic lime mortar samples: Does the hygric interface resistance dominant the moisture transport? J Build Phys 43(3):208-228. https://doi.org/10.1177/1744259119857762

[29] Zhou X, Desmarais G, Vontobel P, Carmeliet J, Derome D. 2020. Masonry brick-cement mortar interface resistance to water transport determined with neutron radiography and numerical modelling. J Build Phys 44(3):251-271 . https://doi.org/10.1177/1744259120908967. 